\begin{tabular}{|l|l|}
\hline $\begin{array}{l}\text { ESCOLA DE COMUNICAÇÃO, } \\
\text { PUCRS }\end{array}$ & $\begin{array}{l}\text { ARTES E DESIGN } \\
\text { FAMECOS }\end{array}$ \\
& $\begin{array}{l}\text { Revidia, cultura e tecnologia } \\
\text { Revista FAMECOS, Porto Alegre, v. 28, p. 1-12, jan.-dez. } 2021 \\
\text { e-ISSN: 1980-3729 | ISSN-L: 1415-0549 }\end{array}$ \\
\hline https://dx.doi.org/10.15448/1980-3729.2021.1.40024 & \\
\hline
\end{tabular}

CIBERCULTURA

\title{
A diagramática das plataformas digitais
}

The diagram of digital platforms

\section{Sur la diagrammatique des plateformes numériques}

Ednei de Genaro ${ }^{1}$

orcid.org/0000-0003-2923-0195

ednei.genaro@unemat.br

Gustavo Denani²

orcid.org/0000-0002-4649-9797

gsoaro36@uottawa.ca

Recebido em: 26 jan. 2021.

Aprovado em: 20 maio 2021

Publicado em: 30 jun. 2021.
Resumo: Os modelos corporativos vigentes de plataformas digitais, e seus data centers, são formidáveis máquinas de acelerar e controlar fluxos, energias, investimentos e especulações. Esquadrinhamos a natureza diagramática das plataformas - virtual e informe, baseada em forças antitéticas, administrando-servindo vidas em plenas "liberdades de expressão" -, tendo por fundamento os quatro mecanismos de modulação formulados por David Savat: o reconhecimento de padrões, a antecipação de atividades, a organização de antíteses e a programação de fluxos. A partir disso, estabelecemos hipóteses, teses e reflexões acerca do poder das plataformas, de disrupção, de povoamento do tempo e de controles distribuidos, e suas diferentes problemáticas associadas. Isso nos leva a discutir o usuário satisfeito, consignado e resignado, e os limites do uso de termos como manipulação, responsabilidade e privacidade.

Palavras-chave: Plataformas Digitais. Diagrama de Controle. Modulação.

Abstract: The current corporate models of digital platforms and their data centers are formidable machines for accelerating and controlling flows, energies, investments, and speculations. This research article explores the platform's diagrammatic nature - virtual and shapeless, based in antithetical, managing-serving lives in total "freedom of speech" - grounding on the four modulation mechanisms proposed by David Savat: the recognition of patterns, the anticipation of activity, the organization of antitheses and the programming of flows. Based on this, it establishes hypotheses, theses, and reflections about the platforms' powers of disruption, populating of time and distributed controls, as well as their different associated issues. It leads to the discussion regarding the satisfied, consigned, and resigned user and the limits concerning the use of terms such as manipulation, responsibility, and privacy.

Keywords: Digital Platforms. Diagram of Control. Modulation.

Résumé: Les actuels modèles des plateformes numériques, et leurs centres des donnés, sont formidables machines pour accélérer et contrôler les flux, énergies, investissements et spéculations. La présente étude examine la nature de ces plateformes (virtuelles et non formées, fondés sur des forces antithétiques, gérant-servant des vies en pleines «libertés d'expression»), sur la base des quatre mécanismes de modulation formulés par David Savat: reconnaissance de formes, anticipation de activités, organisation des antithèses et programmation des flux. À partir de là, nous établissons des hypothèses, des thèses et des réflexions indispensables sur leur pouvoir des plateformes - la disruption, le reglèment du temps, les contrôles distribués, et leurs différents problèmes associés. Cela nous amène à discuter de l'utilisateur satisfait, consigné et résigné, et des limites de l'utilisation de termes tels que manipulation, responsabilité et privacité.

Mots clés: Plateformes Numériques. Diagramme du Pouvoir. Modulation. 


\section{Nova camada tecnológica}

Com a consolidação da denominada indústria 4.0, a nova etapa da industrialização do planeta - de produção automatizada, uso intensivo de dados e comunicação entre dispositivos conectados -, uma nova camada tecnológica sobrepõe-se às infraestruturas já existentes. Os ambientes de conexões sociotécnicas (coletividades humanas e objetos técnicos), baseados em infraestruturas denominadas plataformas digitais, do mesmo modo que a agricultura foi submetida às máquinas eletrônicas e químicas sintéticas, e os polos industriais às redes de telecomunicação, passam por mecanismos instáveis de descentralizações e de recentralizações informacionais e geopolíticos. A partir das plataformas, encampam-se hoje processos de produção, distribuição e marketing muito mais capilarizados e difusos, combinando economia de escala e de cauda longa. ${ }^{3}$

Plataformas digitais organizam, coordenam e encadeiam on-line produtores, clientes, anúncios, provedores e mercadorias, caracterizando-se, especialmente, pela criação e exploração de públicos e nichos de mercado, frequentemente por meio do oferecimento de serviços e produtos já existentes de formas embrionárias, ou nos quais eram possibilidades inexploradas; não obstante, com inéditos efeitos monopolísticos, de poder informacional e mercantil, tendo, desde os anos 1990, âmago infraestrutural e ideológico no Silicon Valley, região da Califórnia, nos Estados Unidos; mas também, atualmente, em Shenzhen, provincia chinesa de Guangdong, principalmente no que concerne às criações e às explorações de tecnologias de vigilância e de moeda eletrônica.

Interessa-nos neste artigo explicitar alguns parâmetros da lógica e do caráter específicos das plataformas digitais, esquadrinhando impreteriveis hipóteses, teses e reflexões acerca da diagramática delas.

\section{Disrupção}

O exemplo recente, emblemático, conhecido e monopolizante de plataforma digital é o Uber Technologies Inc. Apesar de já existirem antes de seu advento mercados de transporte particulares com táxis autônomos e cooperativas, pode-se dizer que sua efetivação tecnológica e empresarial - a despeito do uso ostensivo, retórico e indefinido que o termo vem sendo usado -, foi disruptiva; isto porque, a partir do conceito de e-hailing, ${ }^{4}$ interrompeu, em diversos niveis, convenções e possibilidades de mobilidade urbana. A praticidade em chamar um motorista, saber de antemão o preço de diferentes pacotes, acompanhar a vinda em tempo real, avaliar seu desempenho, e o pagamento ocorrer em algum momento durante esse processo, atribui ao serviço uma facilidade aparentemente mágica. Tal disrupção não é abonada apenas ao consumidor, mas ao serviço como um todo. Qualquer um, em qualquer espaço e tempo, pode ser um motorista particular (difusão e capilarização). A forma monopolística anterior, por licitação, permissão ou licença municipais, que tornava a profissão condutor de táxis minimamente atraente, torna-se arcaica, assim como a renda mensal que cada viagem garantia, uma vez que os preços, entrelaçando economia de mercado e de cauda longa, passam a ser determinados pelos códigos algoritmicos da empresa proprietária da plataforma.

No entanto, há outro exemplo não precisamente de disrupção sobre uma determinada classe ou categoria de trabalho. É o caso das plataformas de entrega de comida, Uber Eats (Uber Technologies Inc.), Rappi (Colômbia), Ifood (Grupo Movile, Brasil), notadamente, que podem ser vistas como intermediárias entre empresas fast-foods e seus consumidores, uma vez que o aplicativo, para o consumidor, é uma feira digital de ofertas. Por outro lado, tais plataformas fomentam uma mão de obra composta por entregadores que, tendo como tarefa elementar se deslocar do ponto A

\footnotetext{
Por cauda longa consideramos a definição de Chris Anderson, grosso modo, o adensamento da cadeia logistica, a descentralização do estoque, e a proliferação de mercadorias digitais, fomentando a emergência de nichos de consumo.

4 O termo inglês hailing significa o aceno que um pedestre faz para chamar um táxi passando em uma rua. E-hailing, pois, a captura e a recodificação da aleatoriedade do ambiente urbano, e a prerrogativa do taxista em responder ao gesto do passageiro em potencial
} 
para o ponto B no menor tempo possível, não é qualificada. Desnecessário dizer que, assim como seus análogos motoristas, a autonomia e a facilidade para se tornar entregador é proporcional à precarização do trabalho. De tal modo, se por um lado é razoável supor que ninguém quer fazer disso uma carreira, por outro é notável a inclinação violenta dessas plataformas para extrair valor de pessoas que, à deriva de políticas neoliberais e de desindustrialização, como no caso brasileiro, teriam dificuldades em obter algum outro tipo de renda.

Um terceiro e último exemplo é o de veículos de locomoção como patinetes e bicicletas. Empresas como a Jump (Uber Technologies Inc.) e a Grin (Grow Mobility Inc.) disponibilizam o uso dos veículos, cada uma com um tipo de cobrança específica; assim, em um único ato de entrega de comida, patrão, entregador e cliente se encontram imersos na disrupção provocada pela cadeia de plataformas de mobilidades que viabilizam o seu serviço: o aplicativo Uber Eats, para o elo entre os três; o Uber Jump, para o transporte em tempo hábil, do entregador e do cliente; o Google Maps, para melhores direções para se locomover; e a lista de plataformas (de mobilidade) cresce - o Airbn (Airbnb, Inc., 2008), para o cliente-viajante receber a entrega em domicilio -, na medida em que novas facilidades e necessidades aparecem, ampliando a ubiquação das plataformas de midias sociais, em suas várias explorações de subjetividades: profissional (LinkedIn, da Linkedln Corporation Inc., 2002), namoro (Tinder, da Tinder Inc., 2012), foto (Instagram, do Facebook, Inc., 2009), vídeo (Youtube, do Google LLC., 2005), filme (Netflix, do Netflix Inc., 1997), música (Spotify, do Spotify Technology S.A., 2006), redes sociais (Facebook, do Facebook, Inc., 2004), mensagem (WhatsApp, do Facebook, Inc., 2009), microblog (Twitter, do Twitter, Inc., 2006), microvideo (TikTok, do Beijing ByteDance Technology Co. Ltd., 2016) e mercadoria (Amazon, da Amazon.com, Inc., 1994; Mercado Livre, do MercadoLibre, Inc., 1999).

\section{Povoamento do tempo}

Apreende-se, pois, que um parâmetro expressivo das plataformas - de mobilidade, sobretudo - é a de precariedade do trabalho, de mudança no espaço urbano, de controle da mão de obra, da infraestrutura e do design que movimentam. Isso já levanta um turbilhão de questões e pautas políticas e acadêmicas dificeis, particularmente para urbanistas e sociólogos.

Ademais, todas as plataformas mencionadas, com destaque às plataformas Facebook, Amazon e Google, têm como ponto fundamental em seus negócios os dados que seus usuários geram. É a partir da acumulação-transformação dos dados que é possivel gerar valor econômico: uma massa de clientes com desejos de consumo a serem satisfeitos (e, não raro, produzidos), e uma massa de despossuidos a ser mobilizada em troca de alguns trocados por hora. Os entregadores e motoristas são exemplos notáveis, na medida que encompassam transportes e serviços na zona cinzenta entre o público e o privado da sharing economy. Mas a precariedade está à espreita de qualquer um. Basta lembrar do Amazon Mechanical Turk e seus análogos como a Leapforce e fazendas de clicks, que "exploram as novas terras da internet, sem necessidade de realizar apropriações rígidas, tampouco produzir conteúdo" (PASQUINELLI, 2009, p. 10, tradução nossa) ${ }^{5}$ - somente via mensuração das inteligências coletivas que produziram os dados. Na nova teoria da renda capitalista, os dados capturados sobre seus usuários são um reservatório de rastros para que se extraia sentidos; e tais sentidos são, essencialmente, probabilidades de futuros possiveis para tomadas de decisões, que podem ser tanto para aprofundar uma determinada tendência quanto para evitá-la.

A axiomática é: "corpos que não geram códigos, ao menos na perspectiva da modulação, não existem. Quanto mais conectado torna-se o mundo, mais códigos geram os corpos, inclusive em nivel biológico" (SAVAT, 2013, p. 44, tradução nossa). ${ }^{6}$ Os

\footnotetext{
5 Do original: [...] exploiting the new lands of the internet with no need for strict enclosures and no need to produce content too.

6 Do original: [...] bodies that do not generate code, at least from the perspective of modulation, do not exist. The more wired the world becomes, the more code bodies will generate, including on the biological level.
} 
códigos transbordam as infraestruturas iniciais, englobando sistemas logísticos, sexuais-afetivos, políticos, entre outros; todavia, não sem o reconhecimento e a captura de certos padrões de código, seja no usuário que surfa por imagens e perfis do Tinder ou no que dirige pela malha rodoviária tendo como guia a plataforma de navegação Waze (Waze Mobile, 2006; Google LLC., a partir de 2013) ou Google Maps (Google LLC., 2005).

Enquanto cartografias potencializadoras de capturas, os diagramas de modulação, embora não pré-definem, são capazes de orientar de maneira muito mais capilar, imersiva - no nivel assignificante, maquínico, não representativo ou discursivo do sujeito (LAZZARATO, 2014). Diferentemente da arquitetura disciplinar, a captura por modulação não se faz a partir de espaços físicos povoados como a prisão, a fábrica ou a escola, mas sim povoando o tempo. Isso é um predicado elementar do poder de modulação das sociedades de controle, podendo ser compreendido, como aclarou David Savat (2009, 2013), por quatro mecanismos: o reconhecimento de padrões, a antecipação de atividades, a organização de antiteses e a programação de fluxos. Pode-se inferir que esses mecanismos se dão em diferentes partes da infraestrutura de uma plataforma. No nivel do usuário, os códigos se manifestam na interface gráfica de um aplicativo e na coleta de metadados que se concorda em ceder nos Termos de Uso, de modo que os arranjos diagramáticos, regra inviolável das plataformas, de captura da subjetivação por domínios pré-individuais, somáticos, anteriores às formações de emoções e consciências (MASSUMI, 2002), emergem dos processos intensivos e recursivos, por meio dos quais inconsciente e afeto entrelaçam-se em temporalidades computacionais.

\section{Sistemas distribuidos de controle}

Os processos intensivos e recursivos, porém, não incidem apenas sobre o usuário. Os diferentes modos de estruturar algoritmos computacionais, bancos de dados e outros objetos digitais permitem uma flexibilização na padronização e na organização de projetos e na composição das equipes de desenvolvimento de software. A tecnologia de desenvolvimento de software Git plataforma GitHub (GitHub, Inc., 2008; Microsoft Corporation, a partir de 2018) -, aplicando um sistema distribuido de controle de versões, sinaliza um ponto de inflexão na modulação de sujeitos. A possibilidade de participar de um ambiente colaborativo de desenvolvimento, analisando, testando e aprimorando um código, produz uma explosão no espaço de produção, do escritório da corporação ao quarto do desenvolvedor, e um esfacelamento do tempo, uma vez que a prioridade de atenção sobre as partes de um projeto responde ao jogo de forças composto por prazos, prescrições quanto ao mínimo produto viável, entre outros elementos que qualificam a produção do embrionário dispositivo diagramático do mundo contemporâneo, o software.

Os mecanismos seguintes, subsumidos ao primeiro, pecularizam-no. O segundo, a antecipação de atividades, ganhou evidência nos últimos anos com a popularização de tecnologias de inteligência artificial e sua aplicação em sistemas especialistas para a automatização de tomada de decisões. Além do uso em empresas, este mecanismo foi objeto de repúdio pela possibilidade de implementá-lo em tribunais dos Estados Unidos, automatizando o viés racista contra negros (NOBLE, 2018). Para além da nefasta tecnologia de reprodução de desigualdades históricas, episódios como esse podem ser entendidos, curiosamente, como um contramovimento na transição da disciplina para o controle. Um "in-dividuo" importa mais para a disciplina do que para a modulação, pois essa funciona em termos de predição de padrões, e não na sedimentação de atributos e comportamentos em um corpo, enquanto elemento dividual. De fato, o viés de uma base de dados, ou de um modelo de inteligência artificial treinado com um dataset viciado, não é capaz de antecipar probabilisticamente o próximo ponto de um gráfico, e sim de reiterar o anteriormente dado; ou seja, mais próximo da arquitetura disciplinar que do diagrama de controle por modulação. 


\section{Trabalho enquanto jogo; entretenimento enquanto obrigação}

Lançando mão de uma cronologia dos governos, do soberano, passando ao disciplinar, até ao de controle, poder-se-ia afirmar que, tal como o poder disciplinar liberou o corpo submetido ao soberano a um potencial produtivo aderente ao capitalismo industrial, o poder modulatório libera o corpo disciplinado às novas formas de extração de valor. A compreensão da liberação orquestrada, que recai sobre a temporalidade dos sujeitos, demandaria uma crítica por meio da noção de organologia política, capaz de articular autonomia, metaestabilidade e ética. Contudo, a situação atual é muito débil. Um dos sintomas da liberação é a aparente indiferenciação de atividades que, no poder disciplinar, eram (problematicamente) bem delimitadas: o estudo-treino, o trabalho, e o tempo livre. A experiência contemporânea no caráter hibrido dessas atividades pode ser vista no boom da gamificação em meados dos anos 2010, assim como na bola de neve que se tornou o consumo de entretenimento. Sobre este último, são sintomáticas as declarações dos CEOs da Netflix e do Spotify, quando o primeiro diz que o sono é o seu principal concorrente (SULLEYMAN, [2017]); o segundo, que os músicos devem se acostumar a produzir música em maior frequência (DARVILLE, [2020]). O ciclo circadiano enquanto próxima fronteira de extração capitalista aponta para um deslocamento da própria noção de recepção enquanto categoria epistemológica dos estudos de comunicação. Em outras palavras, mesmo que seus olhos, ao passo que percorrem uma tela, os dotem de certa similaridade, um usuário de stream e um telespectador de TV distanciam-se, em um primeiro momento, pelas diferentes materialidades articuladas por cada um deles. Uma novela de horário nobre (e a própria noção de horário nobre) pressupõe um circuito fechado sobre a dimensão simbólica entre produção e consumo: o telespectador negocia o significado daquilo que assiste, ressignifica isso dentro de seu contexto local, e se deixa entregar aos patrocinadores de seu entretenimento. O usuário, por sua vez, não é vendido "em lote", nos moldes de uma atenção sincrônica, coletiva, dispensada pelo seu ancestral, mas em fragmentos, nas recombinações de signos que compõem código binário, coordenadas geográficas, retenção após os primeiros minutos de reprodução, entre outros dados. A oferta massiva de conteúdo passa a ser um convite, geralmente, irrecusável à dissolução do usuário em métricas diversas. Pois é na retroalimentação da recepção, (aceleração da reprodução, avaliação do usuário, recomendações, acervo em constante expansão), na hipertrofia resultante desse circuito, que ela passa a ocupar uma importância menor ao se abordar o usuário submetido à extração das plataformas. Trabalhar como se fosse um jogo; entreter-consumir como se fosse uma obrigação (aqui, a organização das antíteses, para Savat) - e tudo isso a partir do esfacelamento do tempo, análogo ao esfacelamento que o mercado fonográfico vive com o Spotify.

Por não se tratar de uma sequência linear de procedimentos, e sim de pontos distribuidos em um espaço multidimensional, a necessidade de encontrar uma metaestabilidade básica nas plataformas digitais apresenta-se como uma questão de sobrevivência - para os fins mercadológicos. A constituição e a contínua manutenção da metaestabilidade é o que Savat chama de programação dos fluxos, manifestando-se, de maneira especial, na composição do feed que o usuário tem com midias sociais. O design e controle sobre a heterogeneidade caracterizam esses fluxos, utilizando-se de redes de cálculo igualmente heterogêneas, com curadores de conteúdo, sistemas de inteligência artificial e metodologias de gerenciamento, muitas vezes, metonimicamente reduzidos ao elusivo termo, algoritmo.

\section{Sofisticação, crítica e inquietação}

O controle modular das populações a partir de plataformas digitais é, de tal modo, uma configuração exemplar de exercício de poder contemporâneo. Sofisticada, uma vez que é soft power, trabalhando no nivel maquínico, assignificante, abstraindo o poder da ideologia, que "não é mais abrangentel,] não define mais o modo global de 
funcionamento do poder" (MASSUMI, 2002, p. 42); 7 irreversivel, levando em conta sua eficiência lógica tecnológica elementar (afinal, seria um tipo de militância um tanto quanto excêntrica privilegiar o táxi em vez do Uber, ou pagar por um servidor de e-mail); criticável, em sua lógica político-econômica, quando ratifica a norma neoliberal, de delegação irrestrita de poder às corporações em detrimento da sociedade civil, do poder público de decisões organológicas; e inquietante, filosófico-politicamente, uma vez que tal controle modular se nutre abertamente - enquanto efeito da atual inépcia em organizar e constituir valores e políticas mais solidárias e democráticas, das subjetividades contemporâneas.

Contudo, o controle modular não é unidirecional, e não serve a um único conglomerado. Enquanto grupos econômicos corporativos, as proprietárias de plataformas digitais gerenciam seus capitais, e, nas suas relações intercapitalistas, podem opor-se, cooperar, fundir-se. Por isso, uma determinada base de dados pode ser ela própria uma mercadoria a ser vendida, roubada ou usada por um interessado que não a plataforma originária. Mercadoria esta cujo valor depende do potencial de extração de relações entre os dados que ela contém. Em sintese, os algoritmos que analisam a massa de dados são como peneiras que separam o ouro do resto dos minérios sem valor.

A via de mão dupla da presumida gratuidade - das plataformas, que cedem o uso pleno ou parcial de serviços, e dos usuários-trabalhadores, que produzem a montanha de dados-tarefas que os controlam-exploram -, é o trunfo do novo modelo de negócios. Aqui a crítica e a inquietação são mais bem apreendidas. Para a ação racional econômica das subjetividades contemporâneas, são bem-vindas as facilidades, a autonomia e as gratuidades oferecidas pelas plataformas. Tomar posição sobre dados produzidos de si, ou mesmo sobre a (pérfida) liberdade de trabalho, é, em vários niveis, estimado irrelevante, ou inconveniente. Trata-se de lidar com o surpreendente e inacessivel "poder dos aplicativos", que explora uma satisfação perspicaz: as antigas maneiras de ouvir música, pedir comida chinesa, conhecer um(a) parceiro(a) sexual são consideradas dispendiosas, se comparadas com os novos hábitos que se entrelaçam com as interfaces dos smartphones, consignando daí o uso da massa de dados para que seja realizado o aperfeiçoamento dessa satisfação. De tal maneira, o êxito das mídias sociais será de renovar a afinidade discursiva entre eles, de mais oportunidades de trabalho e de consumo, à custa da contribuição silenciosa e fantasmal, estimada irrisória para o usuário satisfeito, consignado e resignado.

\section{Além da manipulação}

Decorre que tais, caráter e lógica das plataformas digitais, culminantes em atmosferas de disrupção, controle modular, consignação e resignação, exibem hoje, transversalmente, agudas sequelas sociopolíticas, tendo isso a ver, notadamente, tanto com a desconstrução de ideais de civilidade e de democracia, observáveis em diversos países, quanto com a concessão do exercício de poder via plataformas (de mídias sociais, sobretudo) para fins bem especificos.

As "disrupções eleitorais" manifestadas na eleição de Donald Trump, nos Estados Unidos, na vitória do Brexit, no Reino Unido e, após, de Bolsonaro, no Brasil, são desconfortáveis não apenas pelas diretas consequências políticas, mas, mais profundamente, pela ostentação da descrença em instituições republicanas, democráticas e científicas, a partir de fenômenos socioafetivos reativo, iliberal, provinciano, conservador -, bem dizer, contrafeitos a certos modos operantes da subjetividade contemporânea, apenas. Em particular, tais disrupções eleitorais escandalizaram, de modo muito mais excessivo e questionável, o poder que se pode extrair de uma base de dados para se modular as afetividades políticas de uma população.

Por via de regra, a mesma diagramática que regula o preço de uma viagem no Uber influenciou decisivamente essas eleições. Porém, ater-se à 
condenação da Cambridge Analytica ou de certas deliberações do Facebook; ou seja, isolar culpados pela manipulação e desventura de processos democráticos, seria uma resposta parcial, aquém a uma reflexão critica sobre as materialidades digitais e os actantes envolvidos. A questão vem a ser responder acerca do atual poder de absorção dos indícios da existência de seus usuários (reconhecimento de padrões), em seus relacionamentos diversos e potenciais (antecipação de atividades), em seus regimes de verdade e estados psiconeurológicos (organização das antiteses), a partir da estrutura das plataformas (programação dos fluxos). Vejamos, levando em conta o exemplo supracitado: na sensivel relação de causa e efeito entre a Cambridge Analytica e seus clientes sobreveio um evento afetivo periódico (eleições nos Estados Unidos) e pontual (o resultado do sufrágio), alterando os rumos da sociedade civil e de suas instituições. Apesar de sua pertinência, tal relação não é o fim da modulação de plataformas, tampouco o pior de seus efeitos. A constituição de um usuário afetivamente saturado por signos digitais e o vazio experiencial (ou a recursividade cognitivamente patológica) que se depreendem disso é o solo fértil para a extração de valor a partir do pouco que lhe resta de comportamento emergente, sua débil hipertelia, sua futuração calculável. Dessa forma, o reconhecimento de padrões pode ser entendido como a extração infinitesimal daquilo que ainda não está dado pelo usuário (seu desejo) e sua comunidade; de outro modo, a modelização desses padrões a partir de eventos emergentes, a propagação de um meme ou a formação de grupos interessados em teorias da conspiração são incorporados à variação estatística da norma, por exemplo.

Reduzidos ao consumo e à produção de signos digitais, os elementos que compõem as experiências dos usuários (epistemologias, lembranças, relações) conformam-se às programações de fluxos de cada plataforma. Assim, as vidas social, identitária e econômica, estão fatalmente à deriva dessas redes sociotécnicas, que associam e estimulam afeto e capitalismo nas ações racionais dos indivíduos, desde as interfaces que induzem o olhar e o ritmo de escrita e leitura até a opa- cidade algoritmica que privilegia determinadas narrativas e efetivamente censuram outras. Em outras palavras, a atividade intelectual-afetiva que coedifica a realidade do usuário subsumi à lógica booleana e matemática das plataformas.

Abordar eventos pontuais em termos de manipulação, como é o caso do Brexit e a eleição de Donald Trump, torna-se, pois, problemático na medida em que um sujeito passivel de manipulação está assentado em regimes discursivos, materialidades menos frágeis do que os que um usuário se encontra. Em alguma medida, manipular implica em enganar alguém para reduzi-lo à condição de instrumento, mesmo que por um breve momento. Um usuário, por sua vez, já está integrado em maior ou menor grau às plataformas em que ele consome-trabalha-habita. Por isso, se houve manipulação por parte da Cambridge Analytica ou de Steve Bannon, ela não foi sobre os usuários, e sim sobre a própria plataforma. De modo não determinístico, poder-se-ia dizer que o resultado final desses eventos sugere uma "manipulação" de uma parcela de usuários do Facebook, resultando em uma anomalia estatística. No entanto, pensar aqui apenas em termos de manipulação, mesmo sendo razoável e claro para entender as consequências finais desses eventos, ocultaria a problematização mais adiante e entranhada da modulação e do controle que os possibilitaram.

\section{Desresponsabilização}

Não obstante, as disrupções eleitorais não são fenômenos isolados, uma vez que, na última década, duas forças políticas, ora equivalentes e sinérgicas, outrora antagônicas e conflitantes, ganharam proeminências: o hiperliberalismo acendido na Silicon Valley, instituidor-modelador das plataformas digitais, e os neoconservadorismos nacional-capitalistas, acendidos e nutrindo-se das descentralizações infocomunicacionais e das monetizações geradas pelas mesmas plataformas. A compreensão do novo movimento histórico, complexo, aparentemente antitético e em plena gestação, revela-se fundamental, sobretudo acerca dos problemas da esfera pública e dos direitos humanos. A partir da tribalização (bolhas) e de au- 
tomatização da esfera pública, uma sociedade (in) civil neoconservadora insurge em interpretações afetivas e (ir)racionais da realidade, assombrando pelos assaltos e implosões de dispositivos democráticos. A situação, problemática, marca hoje, por outras vias, os fenômenos de tirania, de ditaduras digitais (HARIRI, 2018) a partir da esfera pública automatizada, e de lutas sociais e parlamentares a favor da social media responsability.

Em relação aos fenômenos acima, é evidente que para se chegar ao golpe decisivo foram necessários esforços de diversos agentes na produção de conteúdos narrativos, desde a criação de comunidades do Facebook sobre teorias da conspiração, pseudociências, histórias "paralelas", negacionistas, até os atuais despejos multiformes bárbaros e anti-iluministas, associaram, paradoxalmente, liberdade de expressão, democracia, fascismo e medievalismo. Como se vê, o problema é intricado e a pergunta é judicial: de quem é a responsabilidade sobre isso? A princípio, para os hiperliberais proprietários das plataformas digitais, em seus explícitos interesses de maximização e de desobrigação acerca dos conteúdos, qualquer material imagético-discursivo, desde que não contrariem o estímulo ao engajamento contínuo do usuário, seria tão somente um meio para o fim delas: fazer o usuário se manifestar; ${ }^{8} \mathrm{em}$ outras palavras, engendrar e acortinar a operação diagramática de servidão maquínica, almejando desonerar-se sobre a sujeição social a partir daquela (LAZZARATO, 2014).

Acima de tudo, em termos da cibernética contemporânea dos corpos, acomete ao animal humano uma renovada natureza da realidade e da relação entre os entes. A atual diagramática de controle é aquela da cibernética sintetizada no conjunto de dados produzidos no correr das interações online, minerados tão logo as programações de fluxos encontram relações de sentido entre séries, acossando a "patologização dos hábitos" (CHUN, 2016). 9 Sob parâmetros e incursões da ciência e da engenharia computacionais, e sob o véu e a isenção da propalada "neutralidade tecnológica" das plataformas, tais relações produzem, com efeito, as novas maquinações de sentido e de presenças humanas (padrões, relevâncias, antecipações, valorizações, agregações, programações, determinações, ocultações e marginalizações); não obstante, como o mesmo fio da meada dos tecelões da primeira Revolução Industrial: a mais-valia, o lucro; ou, atualmente, a mais-valia maquínica das plataformas e a "monetização" dos usuários.

\section{Privar e vigiar}

O véu e a isenção via "neutralidade tecnológica" das plataformas são, exclusivamente, empreendimentos ideológicos. Academicamente, o desvelamento e a crítica vieram, de início, sobretudo a partir dos temas de vigilância e de privacidade. Apesar de temas obviamente relevantes, principalmente no mundo pós-Wikileaks e Snowden, a vigilância e a privacidade remeteram às topologias de poder centralizadas, às imagéticas orwellianas e disciplinares. Porém, a emergência das plataformas e a absorção das infraestruturas infoeconômicas que as precederam implicaram uma mudança sutil, mas em curso, sobre a modulação do eu, em suas dimensões micro e macro, fazendo-se necessário pensar a privacidade (e a vigilância dela) também por outras vias.

Pode-se pensar a privacidade como o direito de um indivíduo - um corpo distinto reconhecido enquanto tal por instituições - seletivamente proteger rastros de sua existência contra terceiros. Tais rastros podem ser de visibilidade, de telecomunicação, de textos e outros tipos de exteriorização que ele possa fazer de sua memória, pressupondo, assim, além de certa noção

\footnotetext{
8 Rememoremos aqui um inestimável comentário de Deleuze, sobre as "interferências" - ou, diriamos, conexões - e a liberdade de expressão: "A besteira [bêtise] nunca é muda nem cega. De modo que o problema não é mais fazer com que as pessoas se exprimam, mas arranjar-lhes vacúolos de solidão e silêncio a partir dos quais elas teriam, enfim, algo a dizer. [...] Do que se morre atualmente não é de interferências, mas de proposições que não têm o menor interesse" (DELEUZE, 1992, p. 161-162).

9 "A habituação autônoma supostamente desconecta. Em contraste, o 'hábito enquanto perda' nos habitua a mudanças constantes, à atualização constante de hábitos necessários para desenvolver novas dependências" (CHUN, 2016, p. 10, tradução nossa). Do original: Autonomous habituation supposedly disconnects. In contrast, 'habit as loss' habituates us to constant change, to the constant updating of habits needed to develop new dependencies.
} 
de individuo, arquiteturas e infraestruturas que permitem fazer-se opaco para outras pessoas e instituições: paredes, janelas, cortinas, linhas telefônicas sem grampo, chaves, senhas para destrancar o celular, contas bancárias, para citar as mais explicitas. A arquitetura de uma casa abriga um corpo, que experimenta a realidade um momento de cada vez. Linhas telefônicas intermediam o diálogo entre dois indivíduos. Senhas e chaves pressupõem uso individual e posse intransferivel. Todas essas tecnologias reforçam uma noção miserável de liberalismo, de posse exclusiva, indício e engodo para termos como autonomia, liberdade e dignidade.

É sintomático como as "filosofias das empresas" de plataformas dão pistas. Em recente conferência sobre os próximos passos do Facebook, seu CEO sintetizou o novo rumo da empresa com o slogan "the future is private".10 "Private", na língua inglesa, possui tanto o sentido de "particular" quanto de "privado", e talvez esse seja o ardil na profecia feita por Zuckerberg, que reconhece o duplo valor dos dados enquanto resíduo da esfera íntima que engloba o usuário e seus grupos de afinidade enquanto uma matéria-prima a ser comercializada, uma propriedade privada a ser vendida, dilapidada por algoritmos e transformada em produto. O slogan ainda insta a suposta autonomia do usuário sobre seus dados - em meio à sua expropriação. Ora, de fato: "a privatização está destruindo o privado, enquanto promove o estado de vigilância e segurança como prisão domiciliar" (CHUN, 2016, p. 12, tradução nossa). ${ }^{11}$

Bruno (2006) sinalizava acerca da tecnopolítica de vigilância em circulação devido às novas infraestruturas da internet, destacando o duplo digital delineado: a produção de perfis do usuário a partir da extração de sua relação com a infraestrutura que ele habita, criando projeção de tendências. As ações poderiam ser tomadas antes que as probabilidades apontadas pelas informações geradas tornassem realidade, efetivando-se um futuro antevisto. O duplo digital seria, pois, o conjunto de dados compondo precisamente o esfacelamento do usuário; ou ainda, um reflexo espectral dele, composto por reduções que o adequam às planilhas e arquivos .json e .xml.

Sabemos que as ações probabilisticas e preditivas dos mecanismos de modulação estabeleceram inéditos agenda-setting e framing midiáticos, com a substituição do broadcast pelo pointcast, tendo como horizonte (estratégias de marketing) um privar e um vigiar enquanto redução da potência da individuação ao provável e criação de "múltiplos sem alteridade" (ROUVROY; BERNS, 2015). De tal modo, os dispositivos de vigilância não seriam mais tecnologias ditas repressivas ou excludentes, mas, em consonância com o horizonte neoliberal, remetendo a uma positividade, ao deixar um corpo se manifestar, fazê-lo falar, contabilizar seus gestos, e, por fim, fazer desta contabilidade um encantamento (habituação patológica) e lucro. Ora, se a nova indústria 4.0, de produção, extração, predição, uso e venda de dados é fecunda e bem-sucedida, destacando-se como inédita concentração de riqueza na história do capitalismo, isso se deu, especialmente, pela e a partir da geração de plataformas digitais que precisamente efetivaram um privar e vigiar enquanto maneira inovadora de captação e controle humanos, já não exclusiva ou subordinada aos poderes estatais, compondo prontamente um original ponto nevrálgico de desterritorialização capitalista.

\section{Anarcocapitalismo}

As atuais corporações empresariais se diferenciam das anteriores pelas formas difusas com as quais conseguem injetar e controlar as modulações, tal como as publicitárias, sendo, por excelência, a linguagem moral contemporânea. ${ }^{12}$ Discursando de maneira mais ampla, poder-se-ia afirmar que os mecanismos de modulação das

\footnotetext{
10 Disponivel em: https://www.theverge.com/2019/4/30/18524188/facebook-f8-keynote-mark-zuckerberg-privacy-future-2019 Acesso em: 3 abr. 2021.

11 Do original: Privatization is destroying the private, while also fostering state surveillance and security as house arrest.

12 "A publicidade é a forma primordial da nossa linguagem moral, aquela que antecipou as formas, os registos, os esquemas da vida moral contemporânea: ela reconheceu o primado do icónico sobre o verbal; compreendeu a natureza psicológica da experiência moral e superou definitivamente o modelo da filosofia da praxis, reconhecendo que a felicidade não é produzida por meio da actuação de um esquema prático [...]" (COCCIA, 2016, p. 123-124).
} 
plataformas digitais corporativas potencializam expedientes anárquicos de "des-territorializações" capitalistas, capazes de implosão e de encampação ininterruptas dos poderes de Estado e da esfera pública, e de fomentação de nova ordem, com efeito de refeudalização e de neocolonialismo cibernéticos do mundo - significando isso os desdobramentos vigentes do fenômeno histórico que há praticamente meio século convencionou-se denominar neoliberalismo. Na gênese do fenômeno histórico, uma obra de 1972 anteviu com toda profundidade a dimensão e a implicação das "des-territorializações" capitalistas, Anti-Édipo: capitalismo e esquizofrenia (DELEUZE; GUATTARI, 2010). Seguem, duas passagens da obra, por suas imensas concisões:

Nunca um Estado perdeu tanta potência para colocar-se com tanta força a serviço do signo de potência econômica. E, apesar do que se diz, o Estado capitalista desempenha este papel desde muito cedo, desde o início, desde sua gestação sob formas ainda meio feudais ou meio monárquicas: controle da mão de obra e dos salários, do ponto de vista do fluxo dos trabalhadores 'livres'; outorga de monopólios, de condições favoráveis à acumulação, luta contra a superprodução, do ponto de vista do fluxo de produção industrial e mercantil [...]. Em suma, a conjunção dos fluxos descodificados, suas relações diferenciais e as suas múltiplas esquizas ou fraturas, exigem toda uma regulação cujo principal órgão é o Estado. O Estado capitalista é o regulador dos fluxos descodificados como tais, enquanto tomados na axiomática do capital (DELEUZE; GUATTARI, 2010, p. 334-335).

Ora, o discurso de desregulamentação é uma falácia ideológica; uma do (cínico) anarcocapitalismo ideologizado no contemporâneo. Estado e empresas entram em simbiose e intercambiam os papéis soberano e regulador, de modo que debates e responsabilidades do âmbito público são enviesados, esvaziados, precarizados, subsumidos na difusa operatividade capitalista. As disrupções provocadas pelas plataformas digitais produziram condições oportunas para a viabilização disso. Em 2014, o Comitê Invisivel (2016), em sintonia com os legados de Deleuze e Guattari, vislumbrou cruciais impasses. A seguir, igualmente, passagens concisas:
Com a nossa concepção de linguística da coisa pública, da política, continuamos os debates enquanto as verdadeiras decisões [são] executadas à nossa vista [...] O poder contemporâneo é de natureza arquitetônica e impessoal, e não representativa e pessoal [...]; è agora imanente à vida, tal como a vida é agora organizada tecnologicamente e mercantilmente (2016, p. 68-69).

Retificariamos, concluindo: diferente de uma arquitetura - que nos lembra mais os dispositivos de confinamento e adestramento dos corpos -, o poder, hoje, é de natureza diagramática virtual e informe, capilarizado, variável, seguindo padrões mutantes e utilizando-se de esquemas de forças antitéticas, que administram-servem vidas em plenas "liberdades de expressão". Os modelos vigentes de plataformas digitais, e seus data centers, são formidáveis máquinas de acelerar e controlar fluxos, investimentos, energias e especulações, decompondo as formas vigentes de Estado e de esfera pública, de modo que o predicado elementar a partir dos aplicativos é o povoamento do tempo das subjetividades e, tão logo, a crescente constituição de meios associados que tendem a satisfazer, consignar e resignar os "usuários". O litígio político não se restringe à responsabilização pública. Evidentemente, a questão que permanece é a do controle; sobre os limites e as armas contra o controle. "O controle é uma vantagem relativa, um processo ininterrupto, ainda que contestável, de refinamento e rearranjo de mecanismos" (MCQUEEN, 2016, p. 4, tradução nossa). ${ }^{13}$ As tecnologias de controle, na medida em que agenciam variados simulacros operativos, aproveitando-se de um moribundo liberalismo, reservado à noção burguesa de privacidade e propriedade, inclinam-se a exaurir o sistema nervoso dos sujeitos com circuitos de recompensa perene, de habituação patológica, preordenando desapropriações e despontencializações. O "véu ideológico" é, em última instância, a ausência de constituição de um materialismo e organologia políticos que se dirijam de fato aos mecanismos computacionais dos softwares, abrindo outros horizontes de design 
e de operações, e oferecendo respostas possíveis a célebre indagação de Catherine Malabou: o que deveríamos fazer para que a consciência do nosso cérebro não seja pura e simplesmente coincidente com o espírito do capitalismo ${ }^{14}$ Se o capitalismo tornou-se mais fundamentalmente operacionalidade maquínica dos afetos (e das dividas) do que ideologia e soberania, o efetivo litígio é, antes de tudo, a luta por um materialismo digital que produza organologias políticas de espaços públicos efetivamente descentralizados e aptos à autogestão - interrompendo a autoridade de senhores feudais cibernéticos.

\section{Referências}

BRUNO, Fernanda. Dispositivos de vigilância no ciberespaço: duplos digitais e identidades simuladas. Revista Fronteiras: estudos midiáticos, São Leopoldo, v. 8, n. 2, p. 152-159, maio 2006

CHUN, Wendy Hui Kyong. Updating to Remain the Same Habitual New Media. Cambridge: The MIT Press, 2016.

COCCIA, Emanuele. O Bem nas Coisas: a publicidade como discurso moral. Lisboa: Documenta, 2016.

COMITÊ INVISIVEL. Aos nossos amigos: crise e insurreição. São Paulo: N-1 Edições, 2016.

DARVILLE, Jordan. Spotify CEO Daniel Ek says working musicians may no longer be able to release music only "once every three to four years". In: The Fader. Nova lorque, 30 jul. 2020. Disponivel em: https://www.thefader. com/2020/07/30/spotify-ceo-daniel-ek-says-working-musicians-can-no-longer-release-music-only-once-every-three-to-four-years. Acesso em: 3 abr. 2021.

DELEUZE, Gilles; GUATTARI, Félix. Anti-Édipo: capitalismo e esquizofrenia. São Paulo: Ed. 34, 2010.

DELEUZE, Gilles. Conversações, 1972-1990. São Paulo: Ed. 34, 1992.

GALLOWAY, Alexander R. The Poverty of Philosophy: Realism and Post-Fordism. Critical Inquiry, Chicago, v. 39, n. 2, p. 347-366, Winter 2013.

HARARI, Yuval Noah. Why Technology Favors Tyranny. In: The Atlantic, Oct. 2018. Disponivel em: https:// www.theatlantic.com/magazine/archive/2018/10/ yuval-noah-harari-technology-tyranny/568330. Acesso em: 3 abr. 2021.

LAZZARATO, Maurizio. Signos, máquinas, subjetividades. São Paulo: N-1 Edições, 2014.

MALABOU, Catherine. What Should We Do With Our Brain? New York: Fordham University Press, 2009.
MASSUMI, Brian. Parables for the Virtual: Movement, Affect, Sensation. Durham: DUP, 2002.

MCQUEEN, Sean. Deleuze and Baudrillard: From Cyberpunk to Biopunk. Edinburgh: EUP, 2016.

NOBLE, Safiya Umoja. Algorithms of Oppression: How Search Engines Reinforce Racism. Nova lorque: New York University Press, 2018

PASQUINELLI, Matteo. Google's PageRank Algorithm: A Diagram of the Cognitive Capitalism and the Rentier of the Common Intellect. In: BECKER, Konrad; STALDER, Felix (org.). Deep Search: The Politics of Search Beyond Google. London: Transaction Publishers, 2009. p. 133-151.

ROUVROY, Antoinette; BERNS, Thomas. Governamentalidade algorítmica e perspectivas de emancipação: o dispar como condição de individuação pela relação? Revista ECO-Pós, Rio de Janeiro, v. 18, n. 2, p. 36-56, jun. 2015.

SAVAT, David. Deleuze's objectile: from discipline to modulation. In: POSTER, Mark; SAVAT, David. Deleuze and New Technology. Edinburgh: EUP, 2009. p. 45-62.

SAVAT, David. The Uncoding the Digital: Technology, Subjectivity and Action in the Control Society. New York: Palgrave Macmillan, 2013.

SULLEYMAN, Aatif. Netflix's biggest competition is sleep, says ceo reed hastings. In: The Independent. Londres, 19 abr. 2017. Disponivel em: https://www.independent.co.uk/life-style/gadgets-and-tech/news/ netflix-downloads-sleep-biggest-competition-video-streaming-ceo-reed-hastings-amazon-prime-sky-go-now-tv-a7690561.html. Acesso em: 3 abr. 2021.

\section{Ednei de Genaro}

Doutor em Comunicação pela Universidade Federal Fluminense (UFF), em Niterói, RJ, Brasil, com período sanduiche no Institut de Recherche et d'Innovation (IRI - Centre Pompidou - Paris); mestre em Sociologia Política pela Universidade Federal de Santa Catarina (UFSC), em Florianópolis, SC, Brasil; professor interino da Universidade do Estado de Mato Grosso (UNEMAT), em Pontes e Lacerda, MT, Brasil.

\section{Gustavo Denani}

Mestre em Meios e Processos Audiovisuais pela Universidade de São Paulo (USP), em São Paulo, SP, Brasil: doutorando em Antropologia pela Universidade de Ottawa (uOttawa), em Ottawa, Ontario, Canada.

\section{Endereço para correspondência}

Ednei de Genaro

Universidade do Estado de Mato Grosso

Rodovia BR 174, Km 209

Zona Rural, 78250-000

Pontes e Lacerda, MT, Brasil 
12/12 Revista FAMECOS, Porto Alegre, v. 28, p. 1-12, jan.-dez. 2021 | e-40024

Gustavo Denani

University Private, 120

Sala 302

Ottawa, Ontario, Canadá

Os textos deste artigo foram revisados pela Poá Comunicação e submetidos para validação do(s) autor(es) antes da publicação. 